\title{
Diagnostic Delay in Ankylosing Spondylitis: Related Factors and Prognostic Outcomes
}

\author{
Sasan FALLAHI, ${ }^{1}$ Ahmad Reza JAMSHIDI ${ }^{2}$ \\ ${ }^{1}$ Tehran University of Medical Sciences, Internal Medicine Division, Baharloo Hospital, Tehran, Iran \\ ${ }^{2}$ Tehran University of Medical Sciences, Rheumatology Research Center, Tehran, Iran
}

\begin{abstract}
Objectives: This study aims to evaluate diagnostic delay, factors which are related to diagnostic delay, and the effect of diagnostic delay on prognostic outcomes in terms of spinal and hip mobility, functional status, disease activity, quality of life, cervical rotation, tragus to wall distance, and sacroiliitis severity in an Iranian population with ankylosing spondylitis (AS).

Materials and methods: One hundred and sixty three patients (129 males, 34 females; mean age $37.74 \pm 9.88$ years; range 18 to 65 years) with AS who met modified New York 1984 criteria were enrolled consecutively in a cross sectional survey. The main outcome variable (diagnostic delay) was defined as the interval between appearance of first symptoms and correct diagnosis of AS. Enthesitis, negative human leukocyte antigen B27 (HLA-B27), and educational level were among the factors of which their relationship to diagnostic delay were evaluated. The prognostic outcomes were measured using Bath ankylosing spondylitis functional index, Bath ankylosing spondylitis disease activity index, AS quality of life, Bath ankylosing spondylitis metrology index, chest expansion, and radiographic sacroiliitis severity.

Results: Diagnostic delay was mean $7.88 \pm 7.17$ years. Diagnostic delay was longer in patients with enthesitis $(8.80 \pm 7.27)$ compared to patients without enthesitis $(6.04 \pm 6.66)(p=0.007)$ and in HLA-B27 negative patients $(10.10 \pm 7.44)$ compared to HLA-B27 positive patients $(7.14 \pm 6.96)(p=0.013)$. Educational level was negatively correlated with diagnostic delay $(p=0.002, r=-0.24)$. Diagnostic delay was correlated with Bath ankylosing spondylitis functional index $(p=0.003, r=0.23)$, Bath ankylosing spondylitis disease activity index $(p=0.026, r=0.18), A S$ quality of life $(p=0.008, r=0.21)$, Bath ankylosing spondylitis metrology index $(p<0.001, r=0.41)$, chest expansion $(p<0.001, r=-0.38)$, and sacroilitis grading $(p=0.042, r=0.16)$.

Conclusion: Negative HLA-B27, enthesitis, and low educational level are factors which affect diagnostic delay in AS. Individuals with enthesitis or low educational level should be evaluated accurately without causing delay in diagnosis since longer delay may lead to poorer prognostic outcomes. Keywords: Ankylosing spondylitis, delayed diagnosis, outcome, quality of life.
\end{abstract}

Ankylosing spondylitis (AS) is a chronic rheumatic disorder characterized by sacroiliac joint and spine involvement with ascending pattern. Peripheral arthritis and extra-articular features are other characteristics which result in severe disability for patients and high medical and societal costs for the governments. ${ }^{1}$ However, diagnosis of this disease is often made with delay in all regions of the world. Delayed diagnosis has been suggested as one of the several factors affecting the prognostic outcomes in AS. This is especially important since this disease has the longest diagnostic delay among other rheumatic diseases, i.e. approximately 5-10 years. ${ }^{2}$ Recent studies showed that patients with shorter disease duration have better response to treatment compared with patients with longer disease duration. ${ }^{3}$ The long disease duration as a result of diagnostic delay may cause patients to miss the chance of early appropriate treatment and consequently have poorer prognosis which include disability, limitation of spinal and hip movements, pain, poor quality of life, and functional status. 
Human leukocyte antigen B27 (HLA-B27) status, educational level, sex, peripheral arthritis, extra-articular manifestations, and family history are some factors reported to affect diagnostic delay in AS; however, their results are inconsistent. ${ }^{4-8}$ Improved knowledge about diagnostic delay status and associated factors in different regions of the world may help clinicians diagnose AS in earlier stages. Earlier diagnosis and efficient treatments with anti-tumor necrosis factor agents may prevent disabilities and improve the outcomes as well as decrease the government healthcare and non-healthcare costs.

Therefore, in this study, we aimed to evaluate diagnostic delay, factors which are related to diagnostic delay, and the effect of diagnostic delay on prognostic outcomes in terms of spinal and hip mobility, functional status, disease activity, quality of life, cervical rotation, tragus to wall distance, and sacroiliitis severity in an Iranian population with AS.

\section{MATERIALS AND METHODS}

This survey was carried out as a prospective cross-sectional study on a total of 163 consecutive AS patients (129 males, 34 females; mean age $37.74 \pm 9.88$ years; range 18 to 65 years) between May 2010 and March 2011. Patients met the modified New York criteria for AS, ${ }^{9}$ and diagnosis was established by a qualified rheumatologist. Informed consents were obtained from all patients. The study protocol was compatible with the latest version of Helsinki declaration and approved by local ethics committee. A structured and pre-designed form was applied for gathering data about the details of disease and recording clinical assessments by the rheumatologist. These data included age, sex, educational level, age at disease onset, age at first diagnosis, disease duration, family history of AS, juvenile/adult onset of disease, peripheral arthritis, enthesitis, associated uveitis, inflammatory bowel disease, nephrolithiasis, history of infection prior to disease onset, HLA-B27, and HLA-B27 subtypes. Age at disease onset was described as the time when the first axial, peripheral arthritis and enthesitis symptoms appeared. Diagnostic delay was defined as the time interval between the first symptoms and correct diagnosis of AS. The HLA-B27 status and HLA-B27 subtypes had been detected in a previous survey by polymerase chain reaction with sequence specific primer with the use of HLA-B27 kit (Olerup SSP AB, Sweden). ${ }^{10}$

Prognostic assessments included functional status, disease activity, quality of life, spinal and hip mobility, fatigue, morning stiffness, finger to floor distance $(\mathrm{cm})$, modified Schober $(\mathrm{cm})$, chest expansion $(\mathrm{cm})$, tragus to wall distance (cm), cervical rotation (degree), intermalleolar distance $(\mathrm{cm})$, and sacroiliitis grading by pelvic radiography (grade II: bilateral erosion, grade III: unilateral or bilateral sclerosis, grade IV: unilateral or bilateral ankylosis). Functional status and disease activity were measured by Bath ankylosing spondylitis functional index (BASFI) and Bath ankylosing spondylitis disease activity index (BASDAI), respectively. ${ }^{11,12}$ In addition, quality of life and spinal and hip mobility were measured by ankylosing spondylitis quality of life (ASQoL) and Bath ankylosing spondylitis metrology index (BASMI), respectively. ${ }^{13,14}$ Fatigue was measured by BASDAI item 1: "how could you describe the overall level of fatigue/ tiredness you have?" (from 0: no fatigue to 10: maximum fatigue). Morning stiffness was measured by BASDAI item 5 (from 0: no morning stiffness to 10: maximum morning stiffness). Validated Persian version of BASFI (from 0: performed without difficulty to 10: impossible to perform), BASDAI (from 0: no activity to 10: maximum activity) and ASQoL (from 0: the best quality to 18: the worst quality) were used. ${ }^{15,16}$ All measurements were performed at the same time of the day and by a single examiner for measurement uniformity.

\section{Statistical analysis}

Frequency (\%), mean \pm standard deviation, median and range were used for presentation of categorical and continuous variables, respectively. Spearman's rho correlation coefficient was used for assessing the factors affecting diagnostic delay and also the relationship of diagnostic delay to prognostic outcomes. Cohen's method was used for exploring the strongest relationship. For comparing diagnostic delay between two or 
more groups of patients, Mann-Whitney and Kruskal Wallis tests were used, respectively. All analyses were performed by PASW version 18.0 for Windows software program (SPSS, Inc., Chicago, IL, USA). $P$ value of $<0.05$ was considered significant in all analyses.

\section{RESULTS}

Of the 163 patients with AS, 74.8\% were HLAB27 positive. The disease had juvenile-onset in 26 and adult-onset in 137 patients. Diagnostic delay longer than five years was observed in 85 patients (52.1\%). Furthermore, 50 patients
(30.7\%) were diagnosed with a delay of at least 10 years. The average diagnostic delay was $7.88 \pm 7.17$ years. Other characteristics and clinical measures were summarized in Table 1.

The average diagnostic delay was shorter in HLA-B27 positive patients than HLA-B27 negative ones $(p=0.013)$ (Table 2$)$. The diagnostic delay was longer in patients with enthesitis compared with the patients without enthesitis $(p=0.007)$ (Table 2). Moreover, educational level was correlated with diagnostic delay $(r=0.24$, $\mathrm{p}=0.002$ ) (Table 3). Diagnostic delay was not significantly different between patients with and without uveitis, inflammatory bowel disease,

Table 1. Description of study group with ankylosing spondylitis

\begin{tabular}{|c|c|c|c|c|c|}
\hline & $\mathrm{n}$ & $\%$ & Mean \pm SD & Median & Range \\
\hline Age (year) & & & $37.74 \pm 9.88$ & 37 & $18-65$ \\
\hline Age at symptom onset (year) & & & $23.39 \pm 7.09$ & 23 & $8-50$ \\
\hline Age at diagnosis (year) & & & $31.28 \pm 9.67$ & 30 & $10-64$ \\
\hline Diagnostic delay (year) & & & $7.88 \pm 7.17$ & 6 & $0-32$ \\
\hline Disease duration (year) & & & $14.49 \pm 8.47$ & 14 & $1-44$ \\
\hline Modified Schober $(\mathrm{cm})$ & & & $3.46 \pm 2.02$ & 4 & $0-10$ \\
\hline BASMI (0-10) & & & $3.95 \pm 1.88$ & 3.6 & $0.6-8.6$ \\
\hline BASFI (0-10) & & & $4.07 \pm 2.74$ & 3.9 & $0-10$ \\
\hline BASDAI $(0-10)$ & & & $4.54 \pm 2.30$ & 4.60 & $0.2-10$ \\
\hline ASQoL $(0-18)$ & & & $8.02 \pm 5.28$ & 8 & $0-18$ \\
\hline Chest expansion $(\mathrm{cm})$ & & & $4.24 \pm 1.94$ & 4 & $0-14$ \\
\hline Cervical rotation (degree) & & & $62.14 \pm 21.07$ & 67.5 & $0-95$ \\
\hline Fatigue (VAS 0-10) & & & $5.23 \pm 2.82$ & 5 & $0-10$ \\
\hline Tragus to wall $(\mathrm{cm})$ & & & $17.91 \pm 6.40$ & 16 & $9-51$ \\
\hline \multicolumn{6}{|l|}{ Educational level } \\
\hline Primary school \& illiterate & 34 & 20.8 & & & \\
\hline Secondary school & 2 & 1.2 & & & \\
\hline High school & 64 & 39.3 & & & \\
\hline University & 63 & 38.7 & & & \\
\hline Juvenile-onset ankylosing spondylitis ( $\leq 16$ years) & 26 & 16 & & & \\
\hline Family history of ankylosing spondylitis & 50 & 30.7 & & & \\
\hline Peripheral arthritis & 83 & 50.9 & & & \\
\hline Enthesitis & 109 & 66.9 & & & \\
\hline Male sex & 129 & 79.1 & & & \\
\hline Inflammatory bowel disease & 11 & 6.7 & & & \\
\hline Uveitis & 23 & 14.1 & & & \\
\hline Intermalleolar distance $(\mathrm{cm})$ & & & $95.42 \pm 24.15$ & 97 & $0-170$ \\
\hline Finger to floor distance $(\mathrm{cm})$ & & & $18.11 \pm 14.52$ & 18 & $0-52$ \\
\hline \multicolumn{6}{|l|}{ Sacroiliitis grading } \\
\hline II & 53 & 32.5 & & & \\
\hline III & 76 & 46.6 & & & \\
\hline IV & 34 & 20.9 & & & \\
\hline Morning stiffness (VAS 0-10) & & & $4.44 \pm 3.10$ & 3 & $0-10$ \\
\hline History of nephrolithiasis & 19 & 11.7 & & & \\
\hline History of infection prior to disease onset\# & 15 & 9.2 & & & \\
\hline Positive HLA-B27 & 122 & 74.8 & & & \\
\hline $\mathrm{B} 27(05)$ & 59 & 36.2 & & & \\
\hline $\mathrm{B} 27(02)$ & 52 & 31.9 & & & \\
\hline B27 (04) & 7 & 4.3 & & & \\
\hline B27 (07) & 4 & 2.5 & & & \\
\hline
\end{tabular}


Table 2. Diagnostic delay of patients by various clinical features

\begin{tabular}{|c|c|c|c|}
\hline \multirow[b]{2}{*}{ Characteristics } & \multicolumn{2}{|c|}{ Delay in diagnosis (year) } & \multirow[b]{2}{*}{$p^{*}$} \\
\hline & Mean \pm SD & Median & \\
\hline $\begin{array}{l}\text { Human leukocyte antigen B27 (+) } \\
\text { Human leukocyte antigen B27 (-) }\end{array}$ & $\begin{array}{r}7.14 \pm 6.96 \\
10.10 \pm 7.44\end{array}$ & $\begin{array}{l}5 \\
9\end{array}$ & 0.013 \\
\hline $\begin{array}{l}\text { Gender } \\
\text { Male } \\
\text { Female }\end{array}$ & $\begin{array}{l}7.67 \pm 6.89 \\
8.71 \pm 8.21\end{array}$ & $\begin{array}{c}6 \\
6.5\end{array}$ & 0.68 \\
\hline $\begin{array}{l}\text { Family history of ankylosing spondylitis (+) } \\
\text { Family history of ankylosing spondylitis (-) }\end{array}$ & $\begin{array}{l}8.36 \pm 6.81 \\
7.67 \pm 7.35\end{array}$ & $\begin{array}{c}6.5 \\
6\end{array}$ & 0.32 \\
\hline $\begin{array}{l}\text { Peripheral arthritis (+) } \\
\text { Peripheral arthritis (-) }\end{array}$ & $\begin{array}{l}8.92 \pm 7.77 \\
6.81 \pm 6.37\end{array}$ & $\begin{array}{l}6 \\
5\end{array}$ & 0.086 \\
\hline $\begin{array}{l}\text { Juvenile onset ( } \leq 16 \text { years) } \\
\text { Adult onset ( }>16 \text { years) }\end{array}$ & $\begin{array}{l}7.88 \pm 8 \\
7.8 \pm 7.04\end{array}$ & $\begin{array}{c}5.5 \\
6\end{array}$ & 0.91 \\
\hline $\begin{array}{l}\text { Enthesitis (+) } \\
\text { Enthesitis (-) }\end{array}$ & $\begin{array}{l}8.80 \pm 7.27 \\
6.04 \pm 6.66\end{array}$ & $\begin{array}{l}6 \\
4\end{array}$ & 0.007 \\
\hline $\begin{array}{l}\text { Uveitis (+) } \\
\text { Uveitis (-) }\end{array}$ & $\begin{array}{l}7.91 \pm 8.03 \\
7.88 \pm 7.06\end{array}$ & $\begin{array}{l}5 \\
6\end{array}$ & 0.71 \\
\hline $\begin{array}{l}\text { Inflammatory bowel disease (+) } \\
\text { Inflammatory bowel disease (-) }\end{array}$ & $\begin{array}{l}8.36 \pm 7.49 \\
7.85 \pm 7.18\end{array}$ & $\begin{array}{l}8 \\
6\end{array}$ & 0.87 \\
\hline $\begin{array}{l}\text { B27 (05) } \\
\text { B27 (02) } \\
\text { B27 (04) } \\
\text { B27 (07) }\end{array}$ & $\begin{array}{c}7.71 \pm 6.86 \\
6.96 \pm 7.51 \\
5.86 \pm 4.85 \\
3.25 \pm 2.63\end{array}$ & $\begin{array}{l}5 \\
5 \\
6 \\
3\end{array}$ & 0.61 \\
\hline $\begin{array}{l}\text { History of nephrolithiasis (+) } \\
\text { History of nephrolithiasis }(-)\end{array}$ & $\begin{array}{l}9.79 \pm 9.16 \\
7.63 \pm 6.87\end{array}$ & $\begin{array}{l}5 \\
6\end{array}$ & 0.44 \\
\hline $\begin{array}{l}\text { History of infection prior to disease onset }(+) \\
\text { History of infection prior to disease onset }(-)\end{array}$ & $\begin{array}{l}6.53 \pm 6.96 \\
8.20 \pm 7.21\end{array}$ & $\begin{array}{l}3 \\
6\end{array}$ & 0.31 \\
\hline
\end{tabular}

peripheral arthritis, family history of AS and past history of infection prior to disease onset. Furthermore, no significant difference was seen between juvenile and adult onset, between male and female patients, and between different HLAB27 subtypes (Table 2).

Diagnostic delay was correlated with the majority of prognostic outcomes including ASQoL, BASFI, BASMI, BASDAI, chest expansion, cervical rotation, tragus to wall and finger to floor distances, modified Schober, intermalleolar distance, morning stiffness, and radiographic

Table 3. Correlations of some characteristics with diagnostic delay

\begin{tabular}{lcr}
\hline & $\begin{array}{c}\text { Spearman's correlation } \\
\text { coefficient }(\mathrm{r})\end{array}$ & $p$ \\
\hline Age & 0.49 & $<0.001$ \\
Age at diagnosis & 0.65 & $<0.001$ \\
Age at symptom onset & -0.11 & 0.163 \\
Disease duration & 0.65 & $<0.001$ \\
Educational level & -0.24 & 0.002 \\
\hline
\end{tabular}

sacroiliitis grading (Table 4). The strongest correlation was observed between diagnostic delay and BASMI, as measured by Cohen's method $(r=0.41, p<0.001)$.

\section{DISCUSSION}

Recent research indicated a long interval between symptom onset and correct diagnosis of AS. The average diagnostic delay was as long as or even longer than that was seen in other areas including Morocco, Turkey, India, Korea, and East of Mediterranean region. ${ }^{4,5,8,17,18}$ However, a study in Italy and also in North West of England showed a longer diagnostic delay. ${ }^{19,20}$

Among several factors evaluated in our survey, HLA-B27 was found as one of the factors which affect diagnostic delay. Positive HLA-B27 may lead to more progressive disease and subsequently, earlier diagnosis. ${ }^{10}$ In addition, positive HLA-B27 may be a reason for evaluating patients more precisely and as a result, may 
Table 4. Correlations between diagnostic delay and prognostic outcomes

\begin{tabular}{lrr}
\hline Outcomes measurements & Spearman's & $p$ \\
\hline Ankylosing spondylitis quality of life (0-18) & 0.21 & 0.008 \\
BASFI (0-10) & 0.23 & 0.003 \\
BASMI (0-10)* & $\mathbf{0 . 4 1}$ & $<\mathbf{0 . 0 0 1}$ \\
BASDAI (0-10) & 0.18 & 0.026 \\
Chest expansion (cm) & -0.38 & $<0.001$ \\
Finger to floor distance (cm) & 0.27 & $<0.001$ \\
Intermalleolar distance (cm) & -0.18 & 0.022 \\
Modified Schober (cm) & -0.33 & $<0.001$ \\
Cervical rotation (degree) & -0.29 & $<0.001$ \\
Fatigue (BASDAI question 1: VAS 0-10) & 0.09 & 0.235 \\
Morning stiffness (BASDAI question 5: VAS 0-10) & 0.21 & 0.006 \\
Tragus to wall (cm) & 0.30 & $<0.001$ \\
Sacroiliitis grading (II, III, IV) & 0.16 & 0.042 \\
\hline BASFI: Bath ankylosing spondylitis functional index; BASMI: Bath ankylosing spondylitis metrology index; BASDAI: Bath ankylosing \\
spondylitis disease activity index; ${ }^{*}$ Bold item denotes strongest correlation.
\end{tabular}

guide physicians to make diagnosis earlier. Shorter diagnosis delay in HLA-B27 positive versus HLA-B27 negative patients has been shown in other studies as well. ${ }^{5,6}$ However, Seo et al. ${ }^{17}$ did not confirm such relationship.

Enthesitis was also shown as another related factor to diagnostic delay in our survey. To our knowledge, such relationship was not observed in other countries. Furthermore, the results of this study revealed that lower educational level causes longer delay in diagnosis. Similar to our results, Dincer et al. ${ }^{5}$ and Gerdan et al. ${ }^{7}$ showed a higher average of diagnostic delay in patients with low educational level compared to high educational level patients. On the other hand, in another survey by Ibn Yacoub et al., ${ }^{8}$ educational level had no effect on diagnostic delay.

Juvenile/adult onset of disease, sex, family history of AS, peripheral arthritis, extra-articular involvement, history of infection prior to disease onset, and HLA-B27 subtypes were not related to diagnostic delay in our study. However, Aggarwal and Malaviya, ${ }^{4}$ Dincer et al. ${ }^{5}$ and Ozgocmen et al. ${ }^{21}$ revealed a longer diagnostic delay in patients with juvenile onset compared to adult onset disease in their surveys. Furthermore, Aggarwal and Malaviya, ${ }^{4}$ Dincer et $a l .{ }^{5}$ and Seo et al. ${ }^{17}$ did not reveal any association between peripheral arthritis or sex and diagnostic delay. Patients with extra-articular involvements had shorter delay in diagnosis in Aggarwal and Malaviya ${ }^{4}$ study. However, this result was not compatible with our survey and Ibn Yacoub et al. ${ }^{8}$ and Seo et al. ${ }^{17}$ studies. Moreover, family history was not related to diagnostic delay in Aggarwal and Malaviya, ${ }^{4}$ and Seo et al. ${ }^{17}$ studies. Conversely, Dincer et al. ${ }^{5}$ demonstrated that patients with family history of AS had shorter diagnostic delay. A comparison of the results of several studies indicates that factors which affect diagnostic delay are not entirely the same in various countries.

The current study revealed correlations between diagnosis delay and the prognostic outcome measurements including ASQoL, BASFI, BASMI, BASDAI, chest expansion, finger to floor distance, intermalleolar distance, tragus to wall distance, cervical rotation, modified Schober, and sacroiliitis grading. The strongest correlation was between diagnostic delay and BASMI (Table 4). Less significant response to treatment owing to delayed diagnosis might be the reason for poorer prognosis in patients with longer diagnosis delay compared to patients with shorter diagnostic delay. These findings for BASDAI, BASFI, and BASMI in this survey are similar to findings of Aggarwal and Malaviya, ${ }^{4}$ and Seo et al. ${ }^{17}$ studies. Similar to our study, Seo et al. ${ }^{17}$ and Salvadorini et al. ${ }^{19}$ showed correlations between diagnostic delay and sacroiliitis severity in their surveys. In addition, relationship of diagnostic delay to BASFI and Bath ankylosing spondylitis radiological index but not to BASDAI was shown in Ibn Yacoub et al. ${ }^{8}$ survey. However, Dincer et al. ${ }^{5}$ did not find such differences between late and early diagnosis groups.

According to our results, diagnostic delay was consistently correlated with the prognostic outcome measurements. However, these 
relationships were not perfectly consistent with previous studies.

Wrong initial diagnoses such as herniated lumbar disk and use of conventional radiography instead of magnetic resonance imaging for diagnosis might be other explanations for delayed diagnosis in AS.7,22 The fact that we did not consider these issues was among limitations of this study which should be noted in future surveys. Furthermore, another limitation was the lack of using radiological assessments, such as Bath ankylosing spondylitis radiological index, as prognostic outcome measurements.

In conclusion, negative HLA-B27, enthesitis and low educational level are the factors which affect diagnostic delay in Iranian patients with AS. Although, HLA-B27 may guide physicians to make correct diagnosis, negative HLAB27 should not be a reason for neglecting clinical manifestations for proper diagnosis. The individuals with enthesitis should be evaluated with caution to prevent missing inflammatory diagnoses, particularly AS. Spending an adequate period of time for taking history and physical examination particularly in patients with low educational level might be essential to make diagnosis as early as possible. The longer the delay is in diagnosis of AS, the poorer will be the quality of life and function, and the more severe will be the disease activity and limitation of spinal and hip mobility. Therefore, emphasis should be placed on to make earlier diagnosis and consequently begin on time appropriate treatment for better prognosis in patients with AS.

\section{Acknowledgments}

The authors gratefully appreciate all participants in the study.

\section{Declaration of conflicting interests}

The authors declared no conflicts of interest with respect to the authorship and/or publication of this article.

\section{Funding}

The authors received no financial support for the research and/or authorship of this article.

\section{REFERENCES}

1. Palla I, Trieste L, Tani C, Talarico R, Cortesi PA, Mosca M, et al. A systematic literature review of the economic impact of ankylosing spondylitis. Clin Exp Rheumatol 2012;30:136-41.

2. Sieper J, Rudwaleit M. How early should ankylosing spondylitis be treated with tumour necrosis factor blockers? Ann Rheum Dis 2005;64:61-4.

3. Rudwaleit M, Listing J, Brandt J, Braun J, Sieper J. Prediction of a major clinical response (BASDAI 50) to tumour necrosis factor alpha blockers in ankylosing spondylitis. Ann Rheum Dis 2004;63:665-70.

4. Aggarwal R, Malaviya AN. Diagnosis delay in patients with ankylosing spondylitis: factors and outcomes--an Indian perspective. Clin Rheumatol 2009;28:327-31.

5. Dincer U, Cakar E, Kiralp MZ, Dursun H. Diagnosis delay in patients with ankylosing spondylitis: possible reasons and proposals for new diagnostic criteria. Clin Rheumatol 2008;27:457-62.

6. Feldtkeller E, Khan MA, van der Heijde D, van der Linden S, Braun J. Age at disease onset and diagnosis delay in HLA-B27 negative vs. positive patients with ankylosing spondylitis. Rheumatol Int 2003;23:61-6.

7. Gerdan V, Akar S, Solmaz D, Pehlivan Y, Onat AM, Kisacik B, et al. Initial diagnosis of lumbar disc herniation is associated with a delay in diagnosis of ankylosing spondylitis. J Rheumatol 2012;39:1996-9.

8. Ibn Yacoub Y, Amine B, Laatiris A, Bensabbah R, Hajjaj-Hassouni N. Relationship between diagnosis delay and disease features in Moroccan patients with ankylosing spondylitis. Rheumatol Int 2012;32:357-60.

9. van der Linden S, Valkenburg HA, Cats A. Evaluation of diagnostic criteria for ankylosing spondylitis. A proposal for modification of the New York criteria. Arthritis Rheum 1984;27:361-8.

10. Fallahi S, Mahmoudi M, Nicknam MH, Gharibdoost F, Farhadi E, Saei A, et al. Effect of HLA-B*27 and its subtypes on clinical manifestations and severity of ankylosing spondylitis in Iranian patients. Iran J Allergy Asthma Immunol 2013;12:321-30.

11. Calin A, Garrett S, Whitelock H, Kennedy LG, O'Hea J, Mallorie P, et al. A new approach to defining functional ability in ankylosing spondylitis: the development of the Bath Ankylosing Spondylitis Functional Index. J Rheumatol 1994;21:2281-5.

12. Garrett S, Jenkinson T, Kennedy LG, Whitelock H, Gaisford P, Calin A. A new approach to defining disease status in ankylosing spondylitis: the Bath Ankylosing Spondylitis Disease Activity Index. J Rheumatol 1994;21:2286-91.

13. Doward LC, Spoorenberg A, Cook SA, Whalley D, Helliwell PS, Kay LJ, et al. Development of the ASQoL: a quality of life instrument specific to ankylosing spondylitis. Ann Rheum Dis 2003;62:20-6.

14. Jenkinson TR, Mallorie PA, Whitelock HC, Kennedy LG, Garrett SL, Calin A. Defining spinal mobility in ankylosing spondylitis (AS). The Bath AS Metrology 
Index. J Rheumatol 1994;21:1694-8.

15. Bidad K, Fallahi S, Mahmoudi M, Jamshidi A, Farhadi $\mathrm{E}$, Meysamie A, et al. Evaluation of the Iranian versions of the Bath Ankylosing Spondylitis Disease Activity Index (BASDAI), the Bath Ankylosing Spondylitis Functional Index (BASFI) and the Patient Acceptable Symptom State (PASS) in patients with ankylosing spondylitis. Rheumatol Int 2012;32:3613-8.

16. Fallahi S, Jamshidi AR, Bidad K, Qorbani M, Mahmoudi M. Evaluating the reliability of Persian version of ankylosing spondylitis quality of life (ASQoL) questionnaire and related clinical and demographic parameters in patients with ankylosing spondylitis. Rheumatol Int 2014;34:803-9.

17. Seo MR, Baek HL, Yoon HH, Ryu HJ, Choi HJ, Baek HJ, et al. Delayed diagnosis is linked to worse outcomes and unfavourable treatment responses in patients with axial spondyloarthritis. Clin Rheumatol 2015;34:1397-405.

18. Slobodin G, Reyhan I, Avshovich N, Balbir-Gurman A,
Boulman N, Elias M, et al. Recently diagnosed axial spondyloarthritis: gender differences and factors related to delay in diagnosis. Clin Rheumatol 2011;30:107580.

19. Salvadorini G, Bandinelli F, Delle Sedie A, Riente L, Candelieri A, Generini S, et al. Ankylosing spondylitis: how diagnostic and therapeutic delay have changed over the last six decades. Clin Exp Rheumatol 2012;30:561-5.

20. Martindale J, Goodacre L. The journey to diagnosis in AS/axial SpA: the impact of delay. Musculoskeletal Care 2014;12:221-31.

21. Ozgocmen S, Ardicoglu O, Kamanli A, Kaya A, Durmus B, Yildirim K, et al. Pattern of disease onset, diagnostic delay, and clinical features in juvenile onset and adult onset ankylosing spondylitis. J Rheumatol 2009;36:2830-3.

22. Rudwaleit M, van der Heijde D, Khan MA, Braun J, Sieper J. How to diagnose axial spondyloarthritis early. Ann Rheum Dis 2004;63:535-43. 